Gazi University
Journal of Science
http://dergipark.gov.tr/gujs

\title{
A Miniaturized Multi-layer Microstrip Antenna for Linear Wireless Sensor Network Monitoring Systems
}

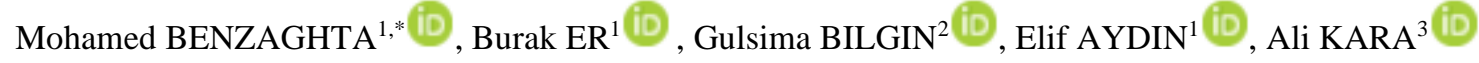 \\ ${ }^{1}$ Department of Electrical and Electronics Engineering, Atilim University, Ankara, Turkey \\ ${ }^{2}$ Department of Electronics and communication Engineering, Toronto University, Toronto, Canada \\ ${ }^{3}$ Department of Electrical and Electronics Engineering, Gazi University, Ankara, Turkey
}

\section{Highlights}

- Gain enhancement using multi-layer antenna.

- The antenna operates at the European license-free ISM band (863-875MHz).

- The antenna meets the harsh environmental conditions of WSNs operating in rural areas.

- The antenna is cost-effective, easy to fabricate and can be employed easily in WSNs.

\section{Article Info}

Received: 05 July 2021

Accepted: 11 Oct 2021

\begin{tabular}{l} 
Keywords \\
\hline ISM band \\
LWSNs \\
Microstrip antenna \\
Miniaturized antenna \\
Multi-layer antenna
\end{tabular}

\begin{abstract}
This article presents a sub-GHz ISM band microstrip patch antenna based on the use of multilayer compact structure, which overcomes the shortcomings of typical microstrip antennas such as low gain and high resonant frequency. The antenna was simulated using an electromagnetic simulator, ANSYS HFSS, and fabricated on two different substrates: RT Duroid 5880 and FR4 epoxy with a compact size of $100 \times 100 \times 8 \mathrm{~mm}^{3}(0.29 \lambda \times 0.29 \lambda \times 0.02 \lambda)$. The simulated results of the antenna were then compared with the measured ones, and the two were observed to have a reasonable agreement. The proposed antenna operates in the sub-GHz license-free ISM band $(862-875 \mathrm{MHz})$, with a gain value of $2.92 \mathrm{~dB}$. Two prototypes of the proposed antenna were fabricated and used in a Linear Wireless Sensor Networks (LWSNs) monitoring system. Results show that the proposed antenna is a good candidate for those types of LWSNs systems.
\end{abstract}

\section{INTRODUCTION}

The favorable properties of microstrip antennas, such as low profile, lightweight, and easy fabrication, have revolutionized the antenna research field. However, their shortcomings of low gain and poor efficiency have made them unsuitable for some wireless communication system applications specially, in sub-GHz frequency bands [1]. To overcome these shortcomings, research on high gain, miniaturized microstrip antennas have received considerable attention in recent years.

In literature, there are proposed methods that enhance the gain of microstrip antennas, most of which are based on increasing the antenna volume [2]. This is achieved by performing modifications to the geometry of the antenna, which increases the volume under the conductive patch. However, enhancement of gain at the expense of increasing the antenna size is not a proper solution for communication systems requiring small and fixed antenna structures to enhance performance and portability.

Another method is to increase the thickness of the substrate using substrate stacking, also known as substrate sandwiching by means of different substrates stacked together. In these methods, the gain is enhanced due to the decrease in effective permittivity [3-8]. Although microstrip antennas using stacked substrate provide a solution for gain enhancement, this will lead to an increase in resonance frequency, 
making these antennas unsuitable for sub-GHz ISM band applications, where such license-free bands are very useful for Linear Wireless Sensor Networks (LWSNs) as in [9].

Wireless Sensor Network (WSN) has been the most common networking service in many applications. Pipeline monitoring is one such application where critical challenges are encountered, especially in oil and gas transportation. Several studies on WSN-based pipeline monitoring have been presented in the literature, specifically for remote monitoring of corrosion in pipelines [9]. When pipeline layouts are considered, WSN needs to be designed in a linear network topology, so-called linear WSN (LWSN), where test posts with built in sensor nodes are placed regularly over the pipeline. Design of low profile, highly directive antennas for LWSN in extreme environments like deserts and high altitudes is a challenge. The only option seems to be microstrip antennas. Nevertheless, as mentioned earlier, microstrip antennas possess certain shortcomings such as, narrow bandwidth, low gain, and poor efficiency. The tradeoff between the parameters, size, bandwidth, efficiency, and gain, regarding the design of small antennas is revealed theoretically by Wheeller [10] and experimentally by [11]. However, as mentioned in [12], most of the miniaturization studies in the literature have been conducted for frequencies of upper $\mathrm{GHz}$ bands.

Several methods have been considered for reducing the resonant frequency of microstrip antennas, as well as size reduction. Slot-loaded patch antennas have proved to be satisfactory in miniaturizing microstrip antennas, and increasing the electrical length of the antenna, thereby producing multiple resonant bands, as well as the reduction of the overall size [13-15]. Also, embedded slots can increase the current path and achieve additional impedance matches. Therefore, with their ability to reduce physical lengths, this method can be used to design miniaturized resonant frequency bands for microstrip antennas as in [16]. Another method is the addition of a parasitic element or in other words shorting pins [17]. A parasitic element antenna design is proposed in [18]. The use of the parasitic element increased the isolation of the antenna by suppressing the surface current at the ground plane of the antenna. However, although slot loaded patch antennas and the use of shorting pins have managed to reduce the antenna size, resonant frequency, and enhance the bandwidth, they still have the shortcoming of reduced overall gain since a major part of the conducting strip is etched out to create the final patch shape.

In this article, we propose a novel multi-layer microstrip antenna structure, using stacked substrates of Rogers 5880 and FR4 epoxy, as a solution for the mentioned shortcomings of microstrip antennas. To the authors' best knowledge, there has been no proposed approach in literature that uses the concept of multilayer stacked substrates as a solution to gain enhancement for miniaturized size microstrip antennas operating at license-free sub-GHz ISM bands $(862-875 \mathrm{MHz})$. The proposed multi-layer design in this study is an enhancement to the authors' proposed antenna structure in [19], in combination with following the miniaturization technique described by the authors' work in [12]. The antenna structure in [19] was not able to meet the requirements of the LWSN applications as in [9] due to its extensive size and complexity in integration with the LWSN monitoring system.

The proposed multi-layer antenna has better gain value while occupying less size compared with previously reported antennas provided in the literature, which operate in the sub-GHz band [20-23]. Two prototypes of the proposed antenna were fabricated and integrated into a LWSN monitoring system as in [9], where such enhanced features are required.

The remainder of the article is organized as follows: Section 2 describes the design methodology where the multi-layer stacked substrate approach is described. Section 3 presents the measured results of the fabricated antenna along with a comparison of the simulated results obtained from the full-wave electromagnetic (EM) simulator, ANSYS HFSS. Furthermore, the implementation of the fabricated antenna in a LWSN application and the achieved results are given in this section as well. In Section 4, discussions and conclusions are provided.

\section{PROPOSED MULTI-LAYER ANTENNA DESIGN}

Multi-layer antenna structure is an efficient and low-cost candidate to overcome the shortcomings of typical microstrip antenna performance used at sub-GHz applications, such as low gain values and higher resonant 
frequencies. The general structure of the proposed multi-layer antenna is shown in Figure 1. The antenna consists of four stacked substrate layers using FR4 substrate $(\mathrm{Er}=4.4)$ for the first three layers and Rogers 5880 substrate $(\mathrm{Er}=2.2)$ for the fourth upper layer. The loss tangent of the FR-4 substrate is 0.02 , whereas the loss tangent of the Rogers 5880 substrate is 0.004 . The thickness of the layers is $1.6 \mathrm{~mm}, 1.6 \mathrm{~mm}$ and $3.2 \mathrm{~mm}$ for the first three FR4 layers, respectively. The fourth and last layer, which has the patch on top of it is of thickness $1.575 \mathrm{~mm}$. The thickness of the radiating conductive part of the antenna patch is $0.035 \mathrm{~mm}$. The dimensions of the upper patch, $\mathrm{H}$-aperture coupling patch, and ground are shown in Figure 2. To provide impedance matching, the size and shape of the $\mathrm{H}$-slot and feeding line are adjusted according to [24]. The dimensions of the feeding line are $8 \mathrm{~mm} \times 40 \mathrm{~mm}$, positioned at the center of the second layer, as shown in Figure 1. The width of the feeding line is determined through parametric analyses to opt for fabrication and impedance matching conditions for $50 \mathrm{ohms} \mathrm{SMA} \mathrm{connector.}$

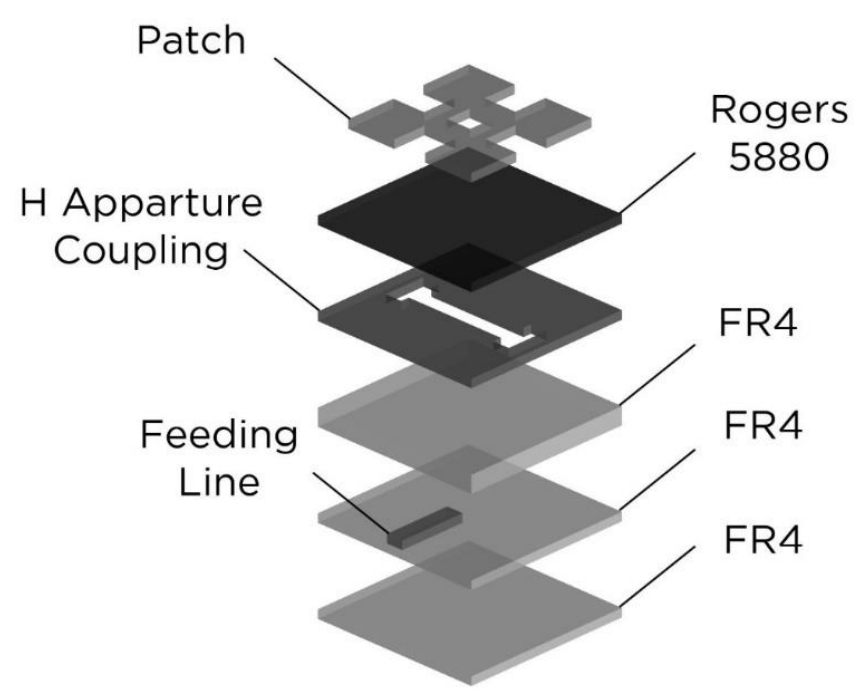

Figure 1. The general structure of the proposed antenna

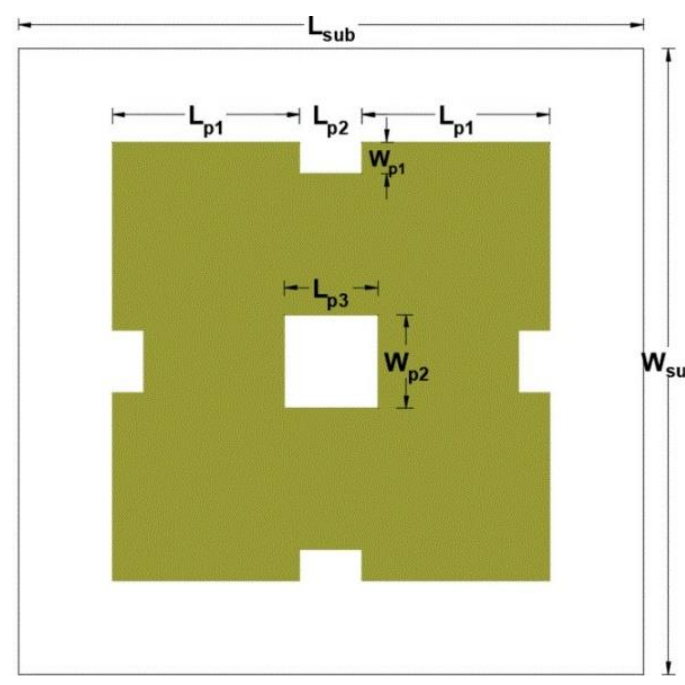

(a)

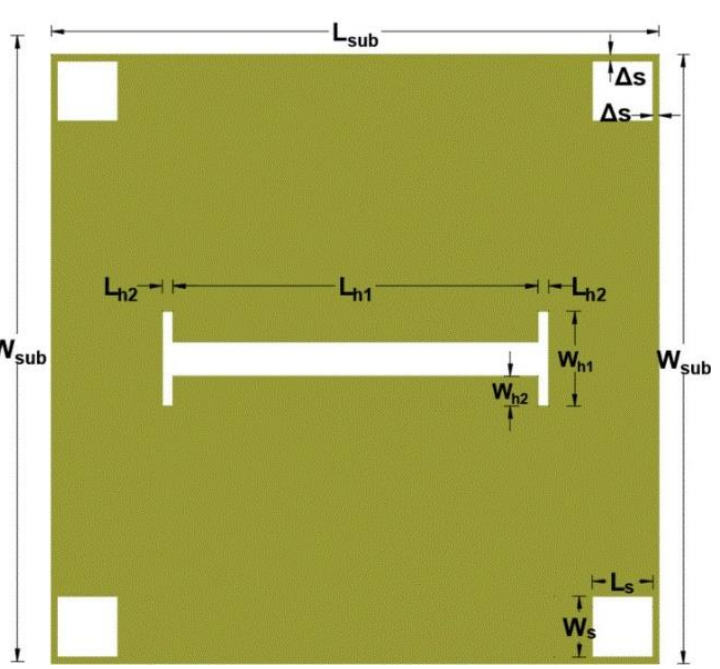

(b) 


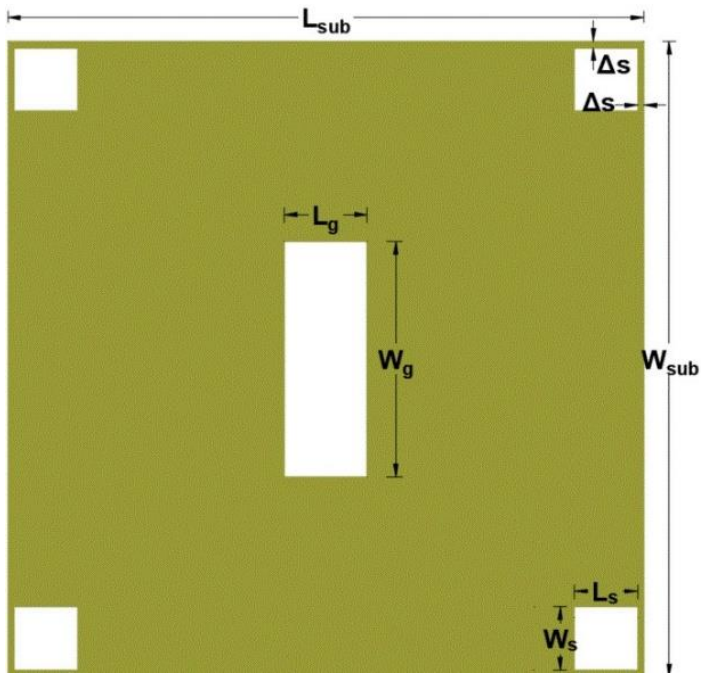

(c)

Figure 2. Antenna patch dimensions a) Top layer patch b) H aperture coupling patch c) Ground plane geometry

To facilitate the design procedure, first, the resonant frequency was determined. Then the patch size was chosen to achieve resonance at the license-free ISM band $(862-875 \mathrm{MHz})$. Steps that were used to design the proposed antenna are based on [25] and can be summarized as follows: Depending on the resonance frequency of the license-free operation band (fo), the thickness (h), the dielectric constant of the substrate $(\mathrm{Er})$ of each layer and the length/width of the patch $(\mathrm{L}=\mathrm{W})$, are calculated as follows [7]:

$$
\begin{aligned}
& \mathrm{W}=\frac{\mathrm{c}}{2 \mathrm{f}_{\mathrm{o}}} \sqrt{\frac{2}{\varepsilon_{\mathrm{e}}+1}} \\
& \mathrm{~h} \leq \frac{0.3 \mathrm{c}}{2 \pi \mathrm{f}_{\mathrm{o}} \sqrt{\varepsilon_{\mathrm{e}}}} \\
& \varepsilon_{\mathrm{e}}=\frac{\varepsilon_{\mathrm{r}+1}}{2}+\frac{\varepsilon_{\mathrm{r}-1}}{2}\left[1+12 \frac{\mathrm{h}}{\mathrm{w}}\right]^{-0.5}
\end{aligned}
$$

where $\mathrm{c}$ is the speed of light in free space, and $\mathrm{Ee}$ is the effective dielectric constant. Also, it should be notated that for a multi-layer structure, the equivalent dielectric constant is obtained as follows [26]:

$$
\varepsilon_{\text {req }}=\frac{\sum_{\mathrm{n}=0}^{\mathrm{N}} \mathrm{t}(\mathrm{n})}{\sum_{\mathrm{n}=0}^{\mathrm{N}}\left(\frac{\mathrm{t}(\mathrm{n})}{\varepsilon_{\mathrm{r}}(\mathrm{n})}\right)}
$$

where $t(n)$ is the height and $\operatorname{Er}(n)$ is the permittivity of the $n$-th substrate.

From the calculation, the following antenna parameters were obtained using ANSYS HFSS: for the top patch dimensions, $\mathrm{L}_{\mathrm{sub}}=\mathrm{W}_{\mathrm{sub}}=100 \mathrm{~mm}, \mathrm{~L}_{\mathrm{p} 1}=30 \mathrm{~mm}, \mathrm{~L}_{\mathrm{p} 2}=10 \mathrm{~mm}, \mathrm{~L}_{\mathrm{p} 3}=15 \mathrm{~mm}, \mathrm{~W}_{\mathrm{p} 1}=5 \mathrm{~mm}$, and $\mathrm{W}_{\mathrm{p} 2}=15 \mathrm{~mm}$; for $\mathrm{H}$-aperture coupling patch dimensions, $\mathrm{L}_{\mathrm{h} 1}=60 \mathrm{~mm}, \mathrm{~L}_{\mathrm{h} 2}=1.8 \mathrm{~mm}, \mathrm{~W}_{\mathrm{h} 1}=15.6 \mathrm{~mm}, \mathrm{~W}_{\mathrm{h} 2}=5 \mathrm{~mm}, \Delta \mathrm{S}=1 \mathrm{~mm}$, and $\mathrm{L}_{\mathrm{S}}=\mathrm{W}_{\mathrm{S}}=10 \mathrm{~mm}$; for ground's slot dimensions, $\mathrm{L}_{\mathrm{g}}=13 \mathrm{~mm}$, and $\mathrm{W}_{\mathrm{g}}=37 \mathrm{~mm}$. 


\section{ANTENNA FABRICATION, MEASUREMENTS, AND IMPLEMENTATION IN LWSN APPLICATION}

According to the procedure described in the design methodology section, the antenna performance is mainly based on return loss, antenna gain, and radiation pattern. These parameters were analyzed using the electromagnetic simulator ANSYS HFSSS before the fabrication process. Figure $3 \mathrm{a}$ and Figure $3 \mathrm{~b}$ show the top and side view of the fabricated antenna. To verify the accuracy of the design, the measurement results were compared with the simulations in terms of return loss, antenna gain, and radiation pattern. The measurements showed that the fabricated antenna had a resonant frequency band of 862-875 MHz, whereas in simulation it was $861-873 \mathrm{MHz}$, as seen in Figure 4. The measured gain value was $2.92 \mathrm{~dB}$. Table 1 compare the proposed antenna in terms of size and gain with other antennas reported in the literature that operate at sub-GHz bands. The proposed antenna has better gain value while occupying less size compared with previously proposed antennas provided in literature, which operate in the sub-GHz band.

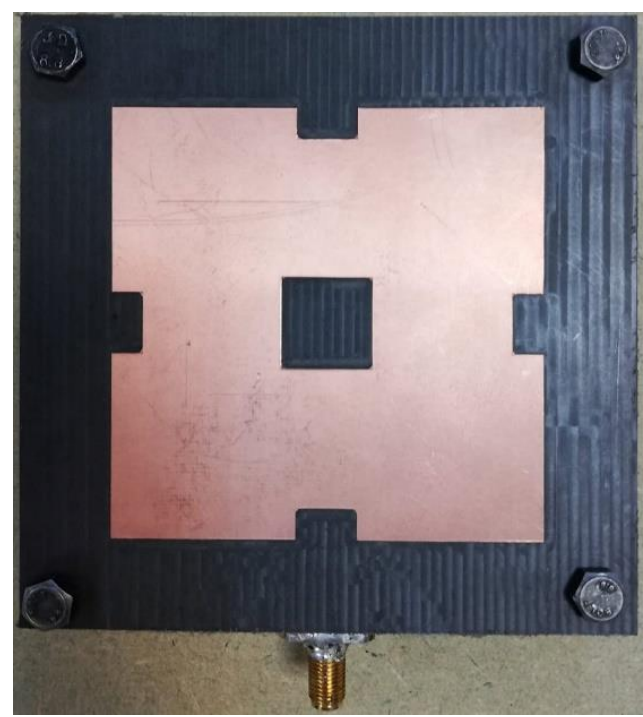

(a)

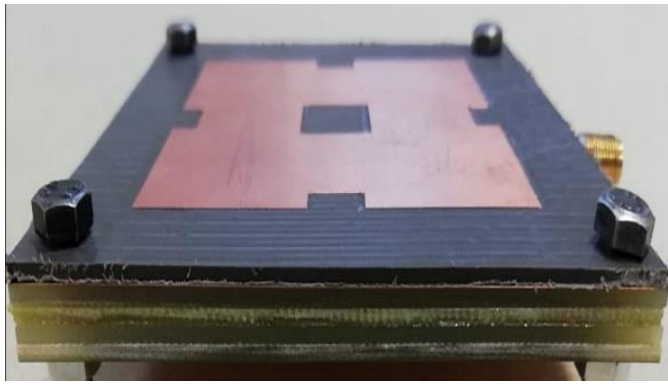

(b)

Figure 3. Fabricated Antenna a) Top view b) Side view

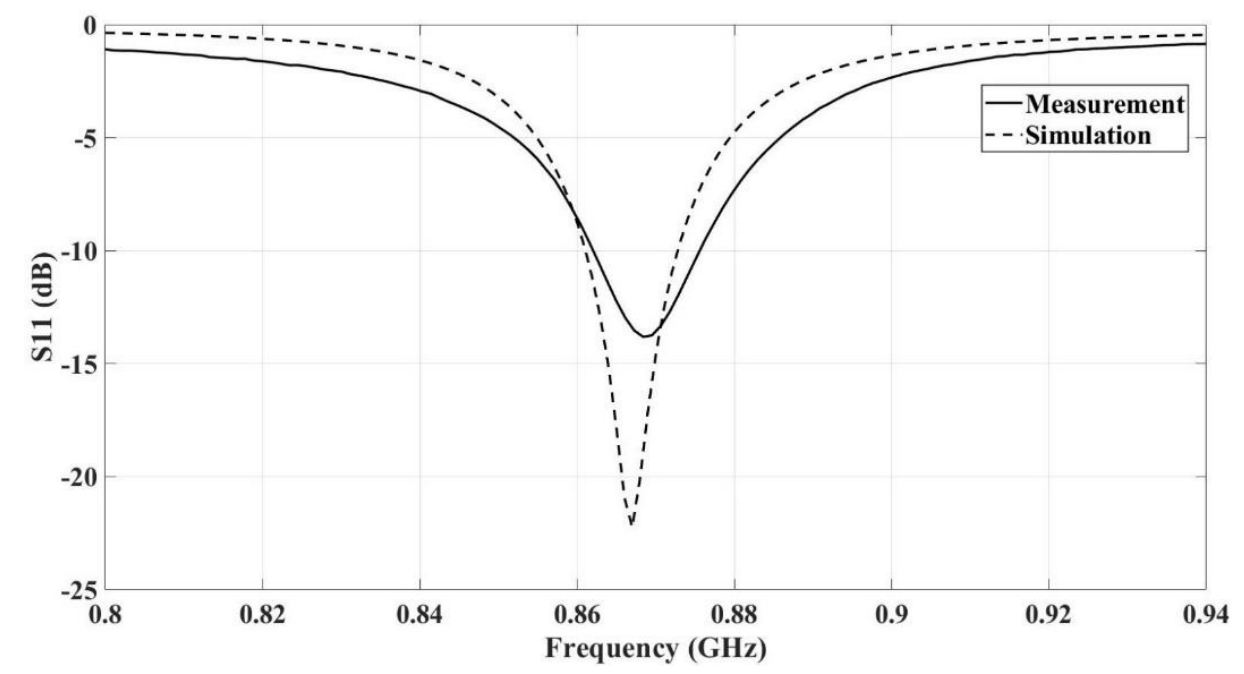

Figure 4. Return loss Vs. Frequency 
Table 1. Performance comparison of the proposed antenna with other reported antennas in literature operating at sub-GHz bands

\begin{tabular}{|c|c|c|}
\hline Ref. & Size $(\lambda)$ & Gain $(\mathbf{d B})$ \\
\hline$[20]$ & $0.36 \lambda \times 0.36 \lambda \times 0.01 \lambda$ & 1.00 \\
\hline$[21]$ & $0.60 \lambda \times 0.61 \lambda \times 0.01 \lambda$ & 1.30 \\
\hline$[22]$ & $0.42 \lambda \times 0.27 \lambda \times 0.01 \lambda$ & 1.68 \\
\hline$[23]$ & $0.45 \lambda \times 0.30 \lambda \times 0.06 \lambda$ & 2.40 \\
\hline proposed & $0.29 \lambda \times 0.29 \lambda \times 0.02 \lambda$ & 2.92 \\
\hline
\end{tabular}

The radiation pattern was also compared to the simulations, as shown in Figure 5. The proposed antenna was designed for use in LWSNs applications as in [9], where unidirectional radiation is expected as two identical antennas are placed back-to-back into a metallic box. As seen from Figures 4 and 5, the measured results show good agreement with the simulations; nevertheless, some minor variations are expected as simulation results represent the best possible parametric optimization, whereas this is not possible in reallife measurements. In practice, when the antenna is installed in the LWSN system, the performance can slightly vary due to the factors such as the metallic box orientation, positioning of the antennas, cabling, and connectors. In addition, the data recorded for the radiation pattern tested in the anechoic chamber was measured at an angle sweep of 5 degrees per measurement, whereas simulation uses an angle sweep of 1 degree per measurement. This makes the simulated radiation pattern more accurate and smoother in graphing.

Two prototypes of the proposed antenna were used in a LWSN monitoring system, using a license-free subGHz ISM band. The sensor node that was used in the LWSN application is based on [27]. The node is composed of Atmel ATmega2560 chips as the microcontroller unit (MCU), SX1276 Radio Frequency (RF) transceiver, and the low-cost, highly accurate DS3231 real-time clock (RTC) chipset. The output power is $17.7 \mathrm{dBm}$, center frequency $865 \mathrm{MHz}$, and bandwidth of $125 \mathrm{kHz}$. The application simply consists of two nodes, a transmitter, and a receiver node. A one meter SMA cable was used to connect each antenna to its node. For testing purposes, 100 packets were sent in different time periods to determine the packet error rate (PER). The average PER results of those experiments are given in Table 2. The experimental results show that the antenna can transmit up to a total distance of more than $3 \mathrm{~km}$, no-line-of-sight (NLOS) propagation, with packet error rate (PER) of less than 1\%, as seen in Table 2. Figure 6 show the position of the transmitter and the receiver antennas in terms of height above mean sea level and separation distance between them.

\section{Azimuth Plane Radiation Pattern}

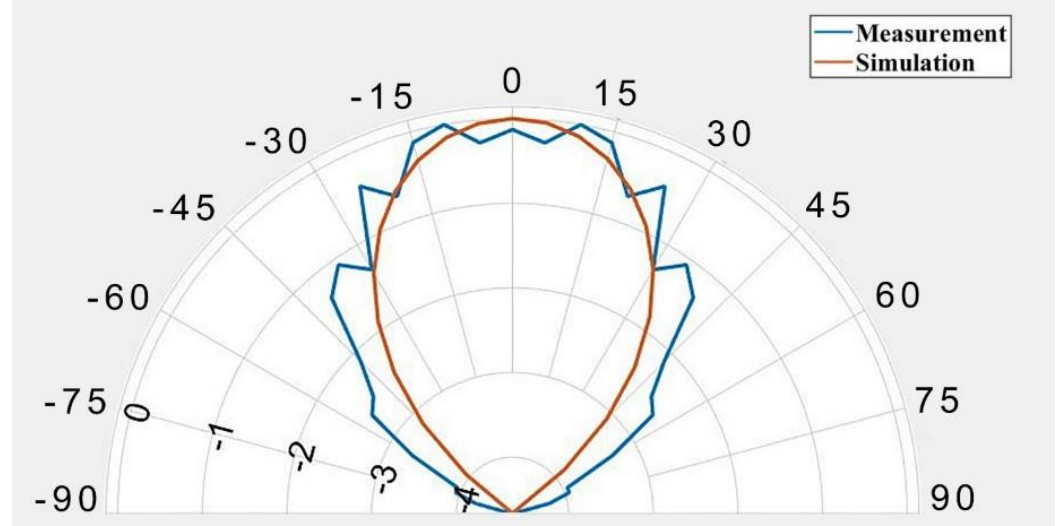

Figure 5. Normalized radiation patterns at $865 \mathrm{MHz}$ 


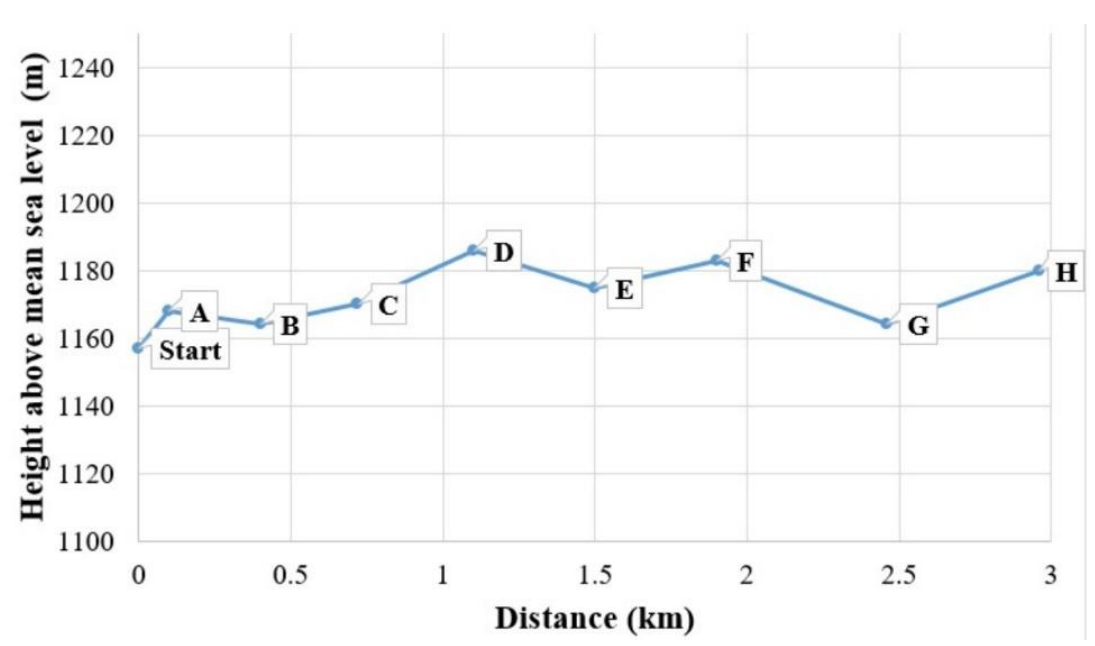

Figure 6. Positioning of the transmitter $(T x)$ and the receiver $(R x)$ antennas when implemented in the LWSN monitoring system

Table 2. Performance when implemented in a LWSN monitoring system

\begin{tabular}{|c|c|c|}
\hline Point & $\begin{array}{c}\text { Distance between Tx } \\
\text { and Rx (km) }\end{array}$ & PER(\%) \\
\hline A & 0.1 & $0.4 \%$ \\
\hline B & 0.4 & $1.5 \%$ \\
\hline C & 0.72 & $0 \%$ \\
\hline D & 1.1 & $0.7 \%$ \\
\hline E & 1.5 & $0.4 \%$ \\
\hline F & 1.9 & $0 \%$ \\
\hline G & 2.46 & $0.7 \%$ \\
\hline H & 2.96 & \\
\hline
\end{tabular}

\section{CONCLUSION}

The aim of this study is to design a miniaturized size microstrip antenna with high gain value for licensefree sub-GHz ISM band applications. A miniaturized multi-layer microstrip patch antenna with a gain of $2.92 \mathrm{~dB}$ was successfully designed and fabricated with dimensions of $100 \times 100 \times 8 \mathrm{~mm}^{3}(0.29 \lambda \times 0.29 \lambda \times$ $0.02 \lambda$ ). The antenna proposed showed better characteristics in terms of size and gain compared to proposed microstrip antennas in literature operating at sub-GHz bands. The simulated and measured results were in reasonable agreement, in terms of comparing return loss, radiation pattern and gain value. The use of multiple stacked substrates in the proposed antenna enhanced the gain value, as well as improved the antenna resistance to harsh environmental conditions making it a good candidate to be used in Linear Wireless Sensor Networks that require such enhanced features.

\section{ACKNOWLEDGMENTS}

This work was financially supported by The Scientific and Technological Research Council of Turkey (TUBITAK) under the grant numbers 5160097 and 116E216. The authors would like to express special thanks to Mr. Ozgur Ozen and Mr. Abdulrrahman Dakhil for their help in different stages of the work. 


\section{CONFLICTS OF INTEREST}

No conflict of interest was declared by the authors.

\section{REFERENCES}

[1] Balanis, C. A., Antenna theory: analysis and design, John Wiley \& Sons, (2016).

[2] Manjunath, G., Sadyojatha, K.M., "Design and analysis of Circular MPA using Multi-layer Substrate Sandwich for bandwidth Enhancement", In 2017 International Conference on Information Communication and Embedded Systems (ICICES), Chennai, India, (2017).

[3] Nejdi, I. H., Rhazi, Y., Lafkih, M. A., Bri, S., "Designing Multiband Multilayered Microstrip Antenna for UMTS, ISM, Communication Satellite, HiperLAN and C-Band", In 2018 International Symposium on Advanced Electrical and Communication Technologies (ISAECT), Kenitra, Morocco, (2018).

[4] Raj, N. A., Dwivedi, R. P., "High gain antenna with DGS for wireless applications", In 2015 2nd International Conference on Signal Processing and Integrated Networks (SPIN), Noida, New Delhi NCR, India, (2015).

[5] Pachauri, N., Gupta, A., Changlani, S., "Analysis of multilayer stacked microstrip patch antenna for bandwidth enhancement", International Journal of Innovative Research in Science, Engineering and Technology, 4(9): 8321-8334, (2015).

[6] Hussein, A. T., Luhaib, S., "Designing E-Shape microstrip patch antenna in multilayer structures for WiFi 5GHz network", In 2012 20th Telecommunications Forum (TELFOR), Belgrade, Serbia, (2012).

[7] Chen, S., Liu, G., Chen, X., Lin, T., Liu, X., Duan, Z., "Compact dual-band GPS microstrip antenna using multilayer LTCC substrate", IEEE Antennas and Wireless Propagation Letters, 9: 421-423, (2010).

[8] Hategekimana, B., and Nithianandam, J., "A wideband multilayer microstrip patch antenna for telemetry applications", Recent Advances on Data Networks, Communications, Computers, (2009).

[9] Kara, A., Al Imran, M. A., Karadag, K., "Linear wireless sensor networks for cathodic protection monitoring of pipelines", In 2019 International Conference on Mechatronics, Robotics and Systems Engineering (MoRSE), Bali, Indonesia, (2019).

[10] Wheeler, H. A., Fundamental limitations of small antennas, Proceedings of the IRE, (1947).

[11] Sievenpiper, D. F., Dawson, D. C., Jacob, M. M., Kanar, T., Kim, S., Long, J., Quarfoth, R. G, "Experimental validation of performance limits and design guidelines for small antennas", IEEE Transactions on Antennas and Propagation, 60: 8-19, (2011).

[12] Yilmaz, V. S., Bilgin, G., Aydin, E., Kara, A., "Miniaturised antenna at a sub-GHZ band for industrial remote controllers", IET Microwaves, Antennas \& Propagation, 13(9): 1408-1413, (2019). 
[13] Turkmen, M., Gunes, Y. E., Hakanoglu, B. G., Yalduz, H., Sen, O., "Dual-Band Patch Antenna with Simple Rectangular Shaped Slots for Local Area Networks", Wireless Personal Communications, (2021).

[14] Hakanoglu, B. G., Koc, B., Sen, O., Yalduz, H., Turkmen, M., "Stub Loaded Patch Antenna and a Novel Method for Miniaturization at Sub 6 GHz 5G and Wi-Fi Frequencies", Advances in Electrical and Computer Engineering, 21(2): 23-32, (2021).

[15] Yang, X., Feng, Q., Zheng, Z., "First-order minkowski fractal circularly polarized slot loop antenna with simple feeding network for UHF RFID reader", Progress In Electromagnetics Research, 77: 89-96, (2018).

[16] Singh, A., Singh, M. K., "Design and Simulation of Miniaturized Minkowski Fractal Antennas for microwave applications", International Journal of Advanced Research in Computer and Communication Engineering, 3: 5309-5311, (2014).

[17] Lai, X., Xie, Z., Cen, X., "Compact loop antenna for near-field and far-field uhf rfid applications", Progress In Electromagnetics Research C, 37: 171-182, (2013).

[18] Yu, B., Jung, C. W., Lee, H., Park, M. J., Kim, B., Wi, H., Lee, B., "Closely mounted compact wideband diversity antenna for mobile phone applications", International Journal of Antennas and Propagation, (2012).

[19] Bilgin, G., Yilmaz, V. S., Kara, A., Aydin, E., "Comparative assessment of electromagnetic simulation tools for use in microstrip antenna design: Experimental demonstrations", Microwave and Optical Technology Letters, 61(2): 349-356, (2019).

[20] Aflaki, P., Xiao, G., Taeb, A., Ye, T., Py, C., "Printed single-feed circularly polarized UHF reader antenna for RFID applications", In 2017 IEEE International Symposium on Antennas and Propagation \& USNC/URSI National Radio Science Meeting, San Diego, California, USA, (2017).

[21] Firmansyah, T., Kurniawan, F., Denny, Y. R., "Multiband microstrip antenna array with slot and array method for GSM, WCDMA, and LTE", In 2017 International Conference on Broadband Communication, Wireless Sensors and Powering (BCWSP), Jakarta, Indonesia, (2017).

[22] Adriandi, G., Wijoyono, D., Pradnyana, K. D., Devara, K., Zulkifli, F. Y., "Microstrip octagonal patch wideband antenna for mobile communication application", In TENCON 2017-2017 IEEE Region 10 Conference, Penang, Malaysia, (2017).

[23] Shi, Z., Ren, W., Liu, H., Chen, K., "Novel "buried-on-wall" 900 MHz cavity-backed slot antenna with circular polarization", Microwave and Optical Technology Letters, 49(12): 3169-3172, (2007).

[24] Pozar, D. M., “A review of aperture coupled microstrip antennas: history, operation, development, and applications", University of Massachusetts at Amherst, (1996).

[25] Bilgin, G., Yilmaz, V. S., Aydin, E., Kara, A., "Design considerations for sub-GHz multilayer microstrip antenna for near ground communication links in rural areas", In 2017 10th International Conference on Electrical and Electronics Engineering (ELECO), Bursa, Turkey, (2017). 
[26] Ali, W. K. W., Al-Charchafchi, S. H., "Using equivalent dielectric constant to simplify the analysis of patch microstrip antenna with multi-layer substrates", IEEE Antennas and Propagation Society International Symposium. 1998 Digest. Antennas: Gateways to the Global Network. Held in conjunction with: USNC/URSI National Radio Science Meeting (Cat. No.98CH36194), Atlanta, GA, USA, (1998).

[27] Al Imran, M. A., Dalveren, Y., Tavli, B., Kara, A., "Optimal operation mode selection for energyefficient light-weight multi-hop time synchronization in linear wireless sensor networks", EURASIP Journal on Wireless Communications and Networking, (2020). 